\title{
The Application of Chinese High-spatial-resolution Remote Sensing Satellite Image in Land Law Enforcement Information Extraction
}

\author{
Ningna Wang*, Rujun Yang \\ Land and Resources Information Center of Guangxi Zhuang Autonomous Region, Nanning, China - (995023479, \\ 1175890842)@qq.com
}

KEY WORDS: land use, high resolution, batch process, geoprocessing model, information extraction, mapping

\begin{abstract}
:
Chinese high -resolution (HR) remote sensing satellites have made huge leap in the past decade. Commercial satellite datasets, such as GF-1, GF-2 and ZY-3 images, the panchromatic images (PAN) resolution of them are $2 \mathrm{~m}, 1 \mathrm{~m}$ and $2.1 \mathrm{~m}$ and the multispectral images (MS) resolution are $8 \mathrm{~m}, 4 \mathrm{~m}, 5.8 \mathrm{~m}$ respectively have been emerged in recent years. Chinese HR satellite imagery has been free downloaded for public welfare purposes using. Local government began to employ more professional technician to improve traditional land management technology. This paper focused on analysing the actual requirements of the applications in government land law enforcement in Guangxi Autonomous Region. 66 counties in Guangxi Autonomous Region were selected for illegal land utilization spot extraction with fusion Chinese HR images. The procedure contains: A. Defines illegal land utilization spot type. B. Data collection, GF-1, GF-2, and ZY-3 datasets were acquired in the first half year of 2016 and other auxiliary data were collected in 2015. C. Batch process, HR images were collected for batch preprocessing through ENVI/IDL tool. D. Illegal land utilization spot extraction by visual interpretation. E. Obtaining attribute data with ArcGIS Geoprocessor (GP) model. F. Thematic mapping and surveying. Through analysing 42 counties results, law enforcement officials found 1092 illegal land using spots and 16 suspicious illegal mining spots. The results show that Chinese HR satellite images have great potential for feature information extraction and the processing procedure appears robust.
\end{abstract}

\section{INTRODUCTION}

China' has been experienced dramatic urbanization in the past decade. Meanwhile, rural illegal buildings, illegal land use and illegal constructions also have been emerged in urban and rural areas, especially in large cities. In order to improve the work efficiency of law enforcement and supervision for land resources, officials of land and resources began to adopt remote sensing technology to solve these problems since 2010. But it cost very expensive for purchasing HR data such as SPOT, WorldView, Geoeye etc. Through comparing images which acquired at various times, detailed land use change can be found with an accurately and rapidly manner. In the past, local land and resources management departments neither afford the price for HR images nor have skilled technicians. But in recent years, domestic HR satellite imagery in China has been freely acquired for public welfare aimed using. For commercial application, the highest spatial resolution of optical data product can reach to $0.5 \mathrm{~m}$.

For GF1, GF2 and ZY3 HR images, the PAN images spatial resolution of them are $2 \mathrm{~m}, 1 \mathrm{~m}$ and $2.1 \mathrm{~m}$, and the corresponding MS images resolution are $8 \mathrm{~m}, 4 \mathrm{~m}$, and $5.8 \mathrm{~m}$ respectively. China's domestic HR satellite image has been used for many aspects so far. For remote sensing monitoring of land use change survey, Weng compared GF1 with SPOT5 and RapidEye from spatial resolution and spectral resolution (Weng et al., 2015). Wu focused on the using of domestic HR images for object-oriented change detection and extraction of construction areas (Wu et al., 2016). Hu used GF1 data for land cover dynamic monitoring (Hu et al., 2016). Since years of practice in land law enforcement, the current situation for remote sensing monitoring is very obvious. Local governments have technical ability for data processing and extracting illegal land utilization information (Lin et al., 2016). For Guangxi government which desired to get illegal land utilization spots timely and effectively, but the local officials' work are generally passive, which caused high administrative accountability and risk. Therefore, this paper focuses 66 counties of Guangxi as study area, through analysing the domestic HR data in the first half of 2016 to monitor land use change, extracting the information by RS, GIS technology and validating the results.

\section{METHODOLOGY}

This research shows the method and experimental result of illegal land utilization spot extraction from fusion Chinese HR images in Guangxi. The procedure contains: A. Defines illegal land utilization spot type. B. Data collection. C. Chinese HR remote sensing image under batch preprocessing. D. Illegal land utilization spot extraction through visual interpretation. E. Obtaining attribute data by ArcGIS GP model. F. Thematic mapping and surveying.

\subsection{Define Illegal Land Utilization Spot Type}

The first and most important thing is to define the illegal land utilization spot type. From Ministry of Land and Resources of China, illegal land use, illegal approval of land use and destroying cultivated land are the behaviour of illegal land utilization, which are also the key point for law enforcement and supervision of land resources. In Guangxi practical work, three types of illegal land utilization spot are defined as follows.

1. First class spot: permanent construction or temporary buildings and structures in the scope of agricultural land

\footnotetext{
* Corresponding author. Ningna Wang, E-mail: 995023479@qq.com
} 
and unused land without authorization, such as buildings, roads and public facilities.

2. Second class spot: recent filling and bulldozing in the scope of agricultural land and unused land without authorization. It always occurred nearby the road and construction land.

3. Third class spot: construction or buildings and structures spots ordered to dismantle last year but still exist in this year.

\subsection{Image Batch Preprocessing}

Data preprocessing for HR images one by one is a traditional way which costs much time and labour. In our research, ENVI/IDL batch progress tool is selected for data preprocessing ENVI is a useful geospatial software solution to process and analyse various types of imagery and data such as multispectral, hyperspectral, LiDAR, and SAR. The secondary development of ENVI is based on its API and IDL. Most image processing functions of ENVI are provided by ENVI Routines or ENVITask, which is also a new object-oriented image processing API model since ENVI version 5.1.

In this research, after downloaded data from website, the following step was data preprocessing which unzipped the files required form data supplier by function FILE_UNTAR. Then orthographic correction was operated by ENVITask ('RPCOrthorectification') with its own RPC file, and the results with WGS84 coordinate system. Certain fine features were only visible on PAN but were difficult to discern on MS. To fully utilize the HR of PAN and rich spectral information of MS, a pan-sharpening process was carried out. ENVITask('NNDiffusePanSharpening') function was adopted to fuse multispectral raster and panchromatic raster. Nearest neighbour diffusion based pan sharpening algorithm for spectral images used the pixel spectrum as its smallest unit of operation and generated resolution-enhanced spectral images using a mixture model, which was different from the most existing algorithms which processed each band separately (Weihua Sun et al. 2014). Custom Task defined by ENVITASK ('GenerateTiePointsByCrossCorrelation'),

('FilterTiePointsByGlobalTransform'), and ENVITASK ('ImagetoImageRegistration') corrected the fusion data to reference data, since the fusion data coordinate system was different from the reference data. The detailed data batch progressing procedure was shown in figure 1.

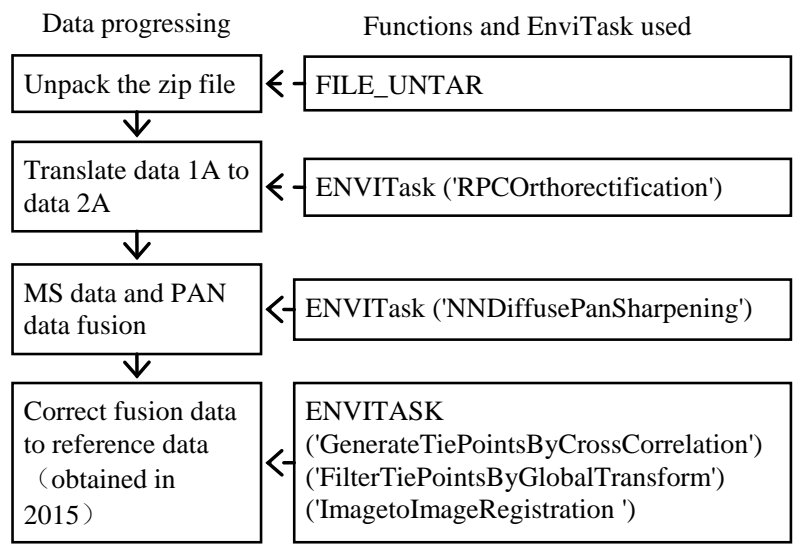

Figure 1. Data batch preprocessing procedure
By running a batch process in ENVI API, this research used a single process (or a chain of processes for that matter) on a list of files, and output results to a location. An ENVI batch script using ENVITasks should contain 5 elements which can make the process work properly.

1. Start ENVI application, preferably in HEADLESS mode since the UI is not needed.

\section{Initialize ENVITask and set constant parameters.}

3. Generate a list of input files to do processing on.

4. Create an output filename - one-to-one match the input file.

5. Run the processing over each file in a loop with the parameters of choice.

\subsection{Illegal Land Use Spots Extraction}

There are three ways for land utilization change detection, including computer interpretation automatically, half-auto computer interpretation and artificial visual interpretation. At present, the mature automatic interpretation methods are mostly based on traditional classification methods, including pixelbased, object-oriented and target-oriented (Blaschke 2010; Bouziani, Goïta, and He 2010; Huo et al. 2010; Tang, Zhang, and Huang 2011). But the accuracy are generally low in practical work because of complicated situations (Chen $G$ et al., 2012), thus aggravate the stuff work in examining the results. Therefore, information extracting from artificial visual interpretation was done according to image contrast of the same region with texture, colour and shape information. ARCMAP 10.3 was used in this research. First, extracting non-constructive areas from land use data and overlaid them on corrected fusion data which acquired in the calendar year of 2016. Second, identifying typical features such as buildings, roads and cultivated land from uncovered part based on object's spatial, spectral, and texture characteristics. Third, comparing the results to the 2015 reference images by swipe tool, created map spot delineation with a vector form (shape file) based on illegal land utilization spot definition which mentioned above. The procedure shows as follows:

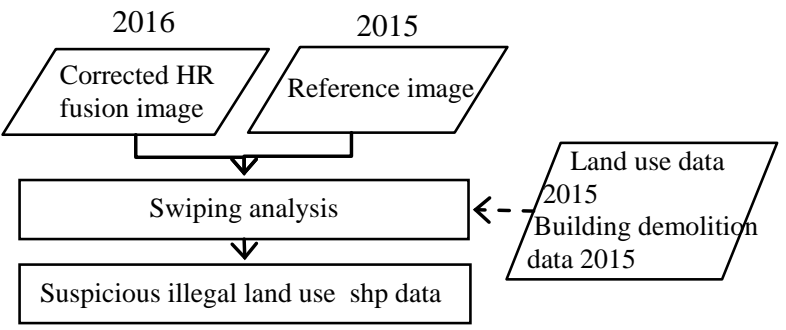

Figure 2. Suspicious illegal land use spots extraction procedure

\subsection{Obtaining Attribute Data by GP Model}

ModelBuilder is a visual programming language for building geoprocessing workflows in ArcGIS. Geoprocessing models can record the spatial analysis and data management processes automatically. This model can be described in the form of combined chains which contains sequences of processes and geoprocessing tools, one output of former process can be used as the input for next process. We created and modified 
geoprocessing models in ModelBuilder to obtain attribute data such as coordinate data, administrative areas, and occupied land areas. Illegal land utilization spot is composed of several land use types such as agricultural land, construction land and unutilized land. Obtaining each land use types' area data model can be described as follows:

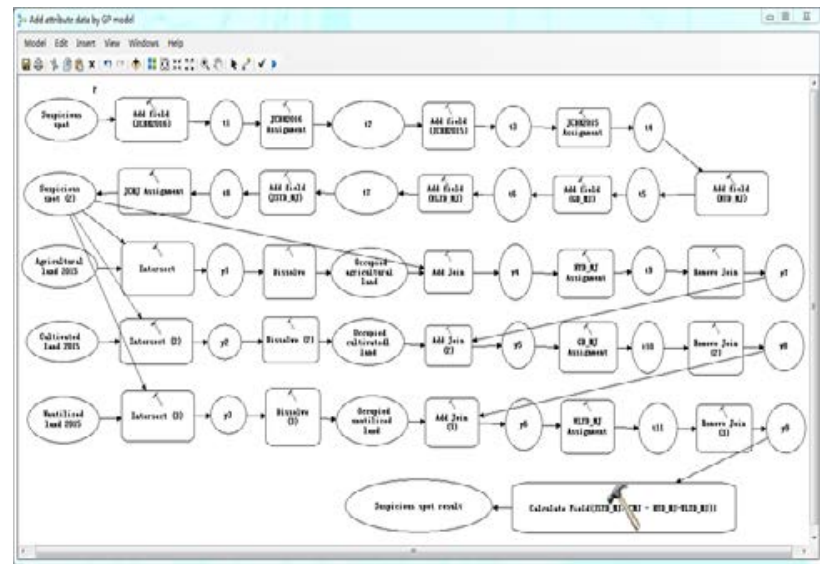

Figure 3. Flowchar of obtaining spot area data model

As shown in Figure 3, the ellipse represents vector data, the square with a hammer represents data processing tool, suspicious spot is illegal land utilization spot, agricultural land, cultivated land and unutilized land are extracted from land use data in 2015. In this model, six fields were firstly added for the illegal land utilization spot vector. JCBH2016 represents ID for each spot, JCBH2015 represents ID for building demolition data. NYD_MJ, GD_MJ, WLYD_MJ, JSYD_MJ, JCMJ represent areas of agricultural land, cultivated land, unutilized land, construction land and illegal land use spot. Then, the manipulation of intersect section can be used to calculate a geometric intersection from input features. The whole or portions of features which overlap in feature classes will be written to output. The manipulation of dissolve part can be used to aggregate features based on specified attributes. The Add Join option here can be used to obtain the administrative region and acquisition time of satellite image. The coordinate of illegal land use spot were calculated based on the values from attribute table. At last, the attribute table were sorted as below.

\begin{tabular}{llllllll}
\hline \multirow{2}{*}{ FID } & Shape & XZQDM & \multirow{2}{*}{ XMC } & $\begin{array}{l}\text { TBL } \\
\text { X }\end{array}$ & QSX & HSX & X \\
\hline \multirow{2}{*}{ Y } & JCBH & JCBH & NYD & GD & WLYD & JSYD & JC \\
& 2015 & 2016 & _MJ & _MJ & _MJ & _MJ & MJ \\
\hline
\end{tabular}

Table 1 . The attribute table of illegal land use spots

\section{EXPERIMENT}

\subsection{Study Area and Data Acquisition}

Our study area is located in Guangxi $\left(20^{\circ} 54^{\prime} \mathrm{N}-26^{\circ} 24^{\prime} \mathrm{N}, 104^{\circ}\right.$ $26^{\prime} \mathrm{E}-112^{\circ} 04^{\prime} \mathrm{E}$ ), south China, with a total area of $236700 \mathrm{~km}^{2}$, totally 111 counties. Most of the area is surrounded by mountain, the central and south regions are mostly flat. ZY3, GF1, and GF2 data between January and August in 2016 were acquired, considering the condition of previous illegal land utilization, 66 counties were selected as hot spots to monitor land use change, and the illegal land utilization spots were extracted based on these analytic results. Figure4 shows the acquired datasets and study area.

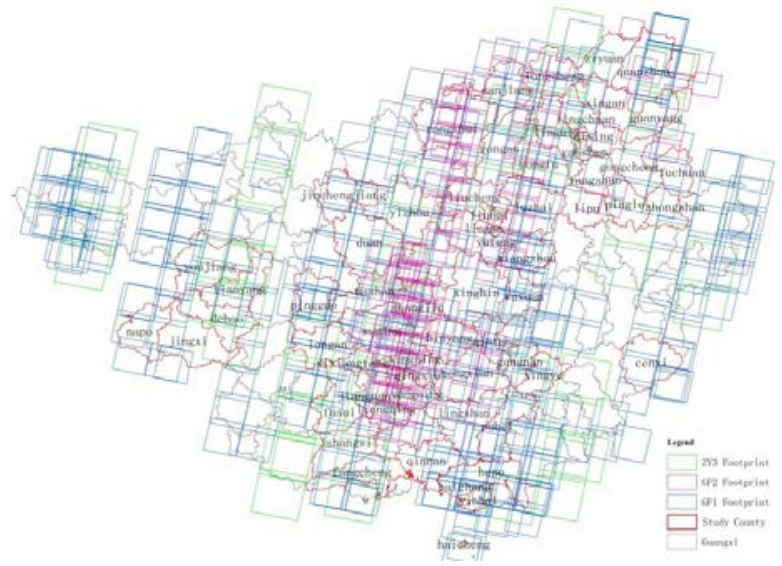

Figure 4. ZY3, GF1, and GF2 footprint in study area in 2016

For public-benefit use, we can freely get GF1, GF2, and ZY3 datasets from Guangxi Bureau of Surveying, Mapping and Geoinformation (State Administration of Science Technology and Industry for National Defence, 2015). The corresponding resolutions of these images are shown in table 2 (China Centre for Resources Satellite Data and Application, 2015).

\begin{tabular}{llll}
\hline & ZY3 & GF1 & GF2 \\
\hline MS data & $6 \mathrm{~m}$ & $8 \mathrm{~m}$ & $4 \mathrm{~m}$ \\
PAN data & $2.1 \mathrm{~m}$ & $2 \mathrm{~m}$ & $1 \mathrm{~m}$ \\
\hline
\end{tabular}

Table 2. Resolutions of ZY3, GF1, and GF2 images
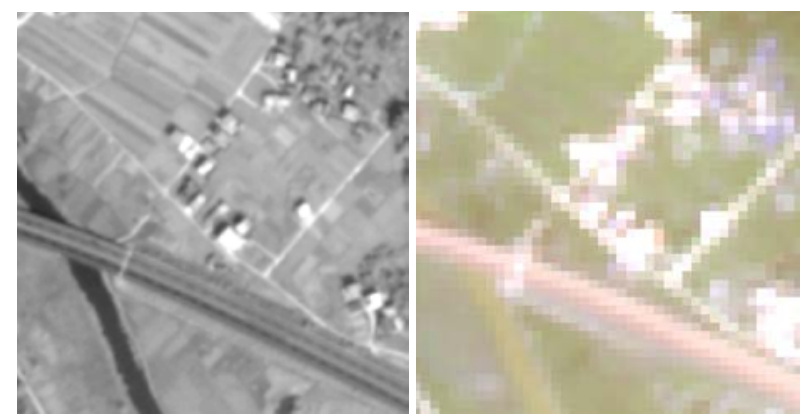

(a) ZY3 Panchromatic image

(b) ZY3 original MS RGB bands
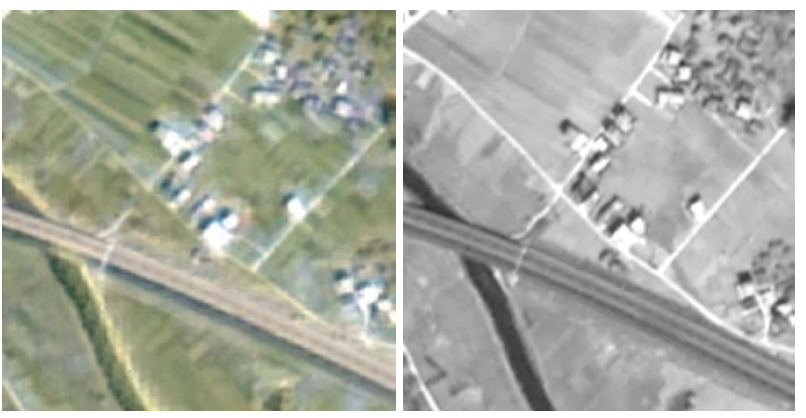

(c) ZY3 fusion RGB bands

(d) GF1 Panchromatic image 


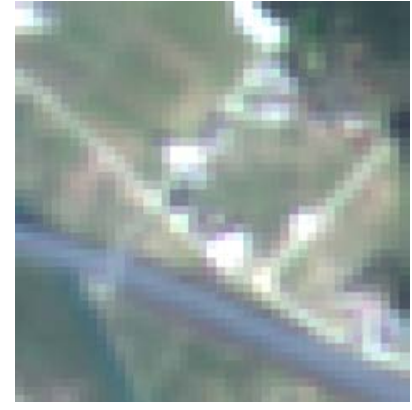

(e) GF1 original MS RGB bands

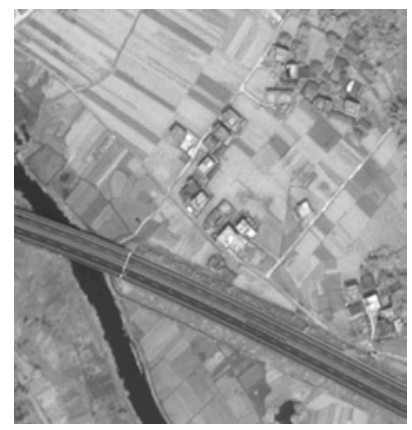

(g) GF2 Panchromatic image

(h) GF2 original MS RGB bands

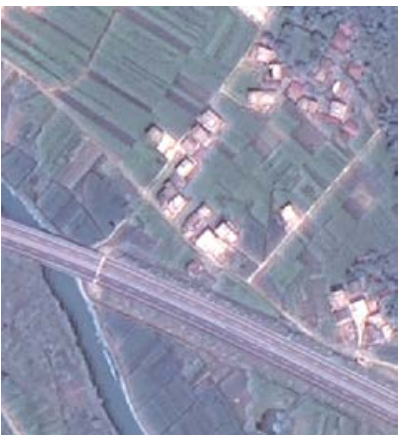

(i) GF2 fusion RGB bands

Figure 5.ZY3, GF1, GF2 panchromatic, multispectral and their corresponding fusion images.

Figure 5 shows panchromatic, multispectral and fusion images of ZY3, GF1 and GF2. The details of these images show the good results of MS data and PAN data fusion, the fused images not only contain the spectral information from multispectral bands, but also the spatial information from panchromatic band. In these images, country road, freeway, buildings, villages, ponds, rivers and farmlands can be recognised clearly and easily. In the process of visual interpretation, illegal land utilization spot can be precisely extracted based on objects' spatial, spectral, and texture characteristics.

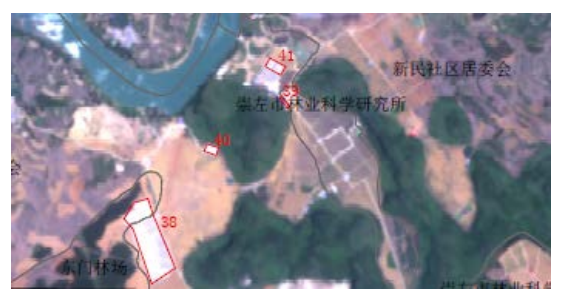

Figure 6. Issued map with suspicious illegal land utilization spot in 1:10000 (red rectangle are suspicious illegal land use spots)

Be limited to cost and labour, the team can't undertake external inspection, so these spots has been issued to local County Land and Resources Management Departments in shape file with an attachment of EXCEL table which has village name, $\mathrm{X}$ Coordinates, Y Coordinates, and the area of spot et al.

Figure 6 also reveals the distribution of spots at the scale of 1:10000. The red polygons are suspicious illegal land utilization spots. Every map has its unique sheet number and village's name and boundaries.

\subsection{Results and Analysis}

In this research, 2958 suspicious spots were produced and posted. After one month of investigation, 53 local County Land and Resources Management Departments fed back the suspicious spots information sheet. The sheets include original land use type, current land use type, and illegal land use areas. 1046 illegal land use spots and 16 illegal mines among suspicious illegal land using spots were verified. The total illegal land use area is $14.81 \mathrm{~km}^{2}$ (cultivated land is $6.52 \mathrm{~km}^{2}$ ). The verified illegal land use spots type include road land, industrial and storage land, public welfare and infrastructure land, rural homestead, and other land use types. The detailed records are shown in Table 3.

\begin{tabular}{|c|c|c|c|c|c|c|}
\hline & Road & $\begin{array}{c}\text { Industrial } \\
\text { and } \\
\text { storage }\end{array}$ & $\begin{array}{c}\text { Public welfare } \\
\text { and } \\
\text { infrastructure }\end{array}$ & $\begin{array}{c}\text { Rural } \\
\text { homestead }\end{array}$ & $\begin{array}{l}\text { Other } \\
\text { land use }\end{array}$ & Total \\
\hline $\begin{array}{l}\text { Number } \\
\text { of spots }\end{array}$ & 241 & 146 & 59 & 207 & 393 & 1046 \\
\hline $\begin{array}{c}\text { Land } \\
\operatorname{area}\left(\mathrm{km}^{2}\right)\end{array}$ & 9.80 & 1.02 & 0.51 & 0.34 & 3.14 & 14.81 \\
\hline $\begin{array}{c}\text { Cultivated } \\
\text { land } \\
\text { area }\left(\mathrm{km}^{2}\right)\end{array}$ & 4.22 & 0.45 & 0.23 & 0.21 & 1.41 & 6.52 \\
\hline
\end{tabular}

Table 3. Verification of illegal land use

13 County Land and Resources Management Departments didn't give further feedback. For the left 53 counties, the accuracy of visual interpretation varies widely. 4 counties with an accuracy of $100 \%, 8$ counties are $80 \%$, and 18 counties less than $20 \%$. From the feedback sheets some spots didn't record any information about the land use. This is why the accuracy rate was not high.

The data preprocessing computer's CPU is Intel i5-2400 dual core. With 40 GF1 images, the tradition way of data preprocessing include rectification, data fusion, which occupied 9.7 days. Through the batching method processing, the time can be reduced to 4.6 days. 


\section{CONCLUSION}

In this paper, ZY3, GF1, and GF2 data were collected from Guangxi Bureau of Surveying, Mapping and Geoinformation freely. Considering the impact of cloudy weather, the obtained data from May to August occupied majority of the total data. According to practical land law enforcement work demand, defining illegal land utilization spot type is essential. In order to save work time and improve efficiency, batch pre-processing method of ENVI software was developed for dealing with Chinese HR remote sensing images. Thereafter, illegal land utilization spots were extracted by visual interpretation with ARCGIS software, this part also the most labour force consuming work. Furthermore, attribute data were obtained from GP model. Finally, the maps were produced and the EXCEL file with locations and other information of suspicious illegal land use spots were also recorded, these results with shape file form were send to local County Land and Resources Bureau. From the feedback information of local County Land and Resources Bureau, the experiment achieved a good result. It meets the significant potential of Chinese HR satellite images applications for land law enforcement. The procedure applied in this paper is efficient. The basic level Law enforcement officials also demonstrated that with the resolution of images improved, the accuracy became higher. With Chinese progress in science and technology, there are more and more HR satellites will be launched, which make the land monitoring work improved greatly with higher accuracy.

\section{REFERENCES}

Blaschke, T., 2010. "Object Based Image Analysis for Remote Sensing." ISPRS Journal of Photogrammetry and Remote Sensing 65 (1):2-16. doi: 10.1016/j.isprsjprs.2009.06.004.

Bouziani, M., Goïta K., and He, D., 2010. "Automatic Change Detection of Buildings in Urban Environment from Very High Spatial Resolution Images Using Existing Geodatabase and Prior Knowledge." ISPRS Journal of Photogrammetry and Remote Sensing 65 (1):143-53. doi: 10.1016/j.isprsjprs.2009.10.002.

Chen, G., Hay G. J., Carvalho, L. M. T., and Wulder, M. A., 2012. "Object-based Change Detection." International Journal of Remote Sensing 33 (14):4434-57. doi: 10.1080/01431161.2011.648285.

China Centre for Resources Satellite Data and Application. Introduction to ZY-3, GF-1 and GF-2 Satellites. (2015-11-03), (2015-11-05), (2015-11-05).

http://www.cresda.com/EN/satellite.

Hu, Q., Zhang, Z., Liu, J., et al., 2016. Research on GF 1 in the Application of the Land Cover Dynamic Monitoring. Geomatics\&Spatial Information Technology, 39(6), pp. 63-66. (Chinese)

Huo, C., Zhou, Z., Lu, H., Pan C., and Chen, K., 2010. "Fast Object-Level Change Detection for VHR Images." IEEE Geoscience and Remote Sensing Letters 7 (1):118-22. doi: 10.1109/LGRS.2009.2028438.

Lin, W., Yu, S., Lin, C., 2016. The Practices of the Land Law Enforcement Inspection Base on the 3S Technology. Beijing Surveying and Mapping, (1) pp. 139-143. (Chinese)
Sun, W., Chen, B., and Messinger, D. W., 2014. "Nearestneighbor Diffusion-based Pan-sharpening Algorithm for Spectral Images." Optical Engineering 53 (1):013107. doi: 10.1117/1.oe.53.1.013107.

Weng, J., Zeng H., Luo, G., 2015. The Application of GF-1 Remote Sensing Image in the Land Use Change Monitoring, Journal of Anhui Agri, 43(16), pp. 358 - 362, 392. (Chinese)

Wu, T., Xia, L., Wu W., et al., 2016. The Application of HighResolution Remote Sensing and Change Detection Technologies in Law Enforcement and Supervision of Land Resources, Journal of Geo-information Science, 18(7), pp. 962968.DOI:10.3724/SP.J.1047.2016.00962. (Chinese)

State Administration of Science Technology and Industry for National Defense. Temporary Measures for the Management of Major Satellite Remote Sensing Data for the Ground Observation System, 2015. Satellite Application (11), pp.71-73. (Chinese)

Tang, Y., Zhang, L., and Huang, X., 2011. "Object-oriented Change Detection Based on The Kolmogorov-Smirnov Test Using High-resolution Multispectral Imagery." International Journal of Remote Sensing 32 (20):5719-40. doi: 10.1080/01431161.2010.507263. 